\title{
STUDY OF PREPARATION METHOD IN ANTIOXIDANTS ANALYSIS FROM KELOR SEEDS (Moringa oleifera L.) TOFU COAGULATION
}

\author{
1Selly Harnesa Putri, ${ }^{2}$ Farah Nuranjani, ${ }^{1}$ Irfan Ardiansah \\ ${ }^{1}$ Lecturer at Department of Agro-industrial Technology \\ ${ }^{2}$ Alumnus of Department of Agricultural Engineering and Biosystem \\ Faculty of Agro-industrial Technology, Universitas Padjadjaran \\ Email: selly.h.putri@unpad.ac.id
}

\begin{abstract}
Currently, Indonesia is exporter of the moringa seed. Moringa seed is a plant which is contain a vegetable oil with many benefits, especially for health. In addition to the utilization of moringa seeds used as vegetable oils, the seeds of this moringa as a natural coagulant, supported by its antioxidant is suitable combined in its use as a natural coagulant on tofu. The analytical method used in the antioxidant content testing using DPPH method is an easy, fast and sensitive method using DPPH free radical (1,1 diphenyl-2-picrilhidrazil). In antioxidant analysis required materials of extract, which high yield and purity consisting of extraction method of multilevel maceration extraction with 3 solvents ( $n$-hexane, 70\% of acetone and 96\% of ethanol) 1: 3 solvent and solvent ratio and Ultrasonic Assisted Extraction (UAE). The result of the research showed that the extraction process using multilevel maceration extraction with high yield and purity. Determination of extract concentration for IC50 calculation measured by using a spectrophotometer so that the percentage of inhibition is 722,01 which concentration needed to $50 \%$ can inhibit free radical in antioxidants analysis. The impact of research results is utilized optimally on extract moringa seeds with many benefits especially for health.
\end{abstract}

Keywords: antioxidant, DPPH method, tofu, moringa seed

\section{INTRODUCTION}

Moringa plants can easily grow in Indonesia because they can grow in lowland to highland areas, as well as in sandy or river areas (Council of Scientific and Industrial Research, 1962 in [6]). According to [6], in Indonesia, the moringa plant was used as a hedge plant and has not been utilized optimally. Scientifically, almost all parts of the moringa plant can be utilized as a useful raw material product in the pharmaceutical, health, chemical, and food industries. One part of the moringa plants that can be utilized i.e. the seeds. According to [1] Moringa seeds are part of Moringa plant which contains high vegetable oil (35\% w/w oil) and has many benefits, especially for health. Moringa seeds can be used as cholesterollowering drugs, reduce the risk of coronary heart disease, cosmetic additives, until it can also be used as meal oil and biodiesel oil. According to [7], The oil characterized by high amounts of oleic acid up to $75 \%$, which make it suitable for edible purposes and due to good oxidative stability, its use in food industry as allowing for longer storage and hightemperature frying processing. The 
characterization of Moringa oleifera seed oil indicates this oil contain high unsaturated fatty acids, which could make it possibly utilized in nutritional and industrial purposes [

Tofu is a food source of protein that has been consumed in Indonesia, in rural and urban communities. It can be optimized as a substitute material of milk, meat and egg protein. It is obtained from the process of protein deposition of the material by the addition of coagulant, in this research is given an alternative use of moringa seeds as natural coagulant is supported by its advantages that high antioxidant.

Various methods of antioxidant activity testing have been used to know and compare antioxidant activity in foods. In recent years, oxygen radical absorbance capacity testing has been used to test antioxidant activity in food, serum and biological fluids. Various methods for the antioxidant activity analysis can be used, one of which is 1,1-diphenyl-2picrilhidrazil (DPPH) is a fast, easy and expensive method to measure antioxidant activity in food with DPPH free radical compounds. The extraction process is carried out to isolate antioxidant compounds. The most common method of extraction is the method of maceration and percolation extraction, but with technology develops, other extraction methods such as extraction using Ultrasonic Assisted Extraction (UAE) and Microwave Assisted Extraction (MAE). In this study will be compared the effectiveness of extraction methods of maceration and extraction using ultrasonic which will be described the advantages and disadvantages from each other.

\section{MATERIAL AND METHOD}

\section{Material}

The materials used in this research consist of main raw materials and chemicals. The following ingredients used in the study antioxidant analysis preparation from tofu coagulation using moringa seed presented in Table 1.

Table 1. Material and The Utility

\begin{tabular}{ll}
\hline \multicolumn{1}{c}{ Material } & \multicolumn{1}{c}{ Utility } \\
\hline Kelor seeds & Coagulant material \\
\hline Soy bean & Raw material \\
\hline Ethanol & $\begin{array}{l}\text { Solvent extraction of } \\
\text { maceration and } \\
\text { Etil acetate }\end{array}$ \\
\cline { 1 - 1 } $\mathrm{Na}_{\mathrm{SO}}$ & Antrasonic \\
\cline { 1 - 1 } $\mathrm{n}$-hexane & \\
\hline AsPH & \\
\hline NaOH & \\
\hline Methanol &
\end{tabular}

\section{Method}

The research method used experimental method of preparation in antioxidant analysis with descriptive analysis. In this research, we observed sample preparation extraction which has high yield and purity, and time efficiency.

The extraction method was a multilevel maceration extraction with 3 solvents (n-hexane, $70 \%$ of acetone and 96\% of ethanol) 1: 3 solvent and solvent ratio, and extraction using ultrasonic (Ultrasonic Assisted Extraction) / UAE (f $20 \mathrm{kHz}, 500 \mathrm{~W}, 30$ minutes, material ratio and solvent $1: 100 \mathrm{~b} / \mathrm{v}$ ).

\section{Research Phase}

In this study of antioxidant preparation analysis from tofu coagulation using seed kelor, consisting of four phases. (1) raw material preparation (2) tofu 
coagulation, (3) tofu extraction, (4) phase of antioxidant activity test contained in the extract.

\section{Raw Material Preparation}

Preparation of raw materials kelor seeds are process of sorting and grading that aims to uniform raw materials to be used in this research. Raw materials of moringa seeds imported from Bekasi, can be seen in Figure 1.

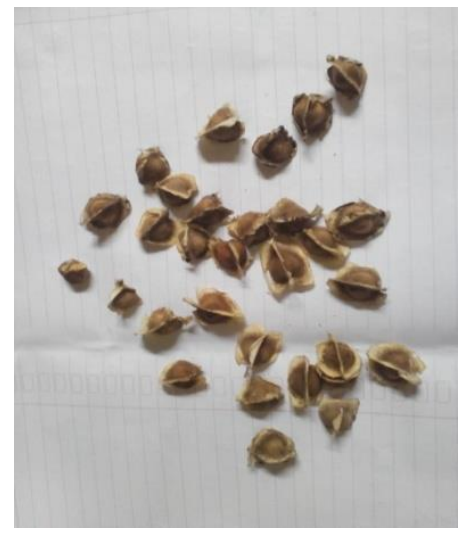

Figure 1. Kelor seeds

\section{Tofu coagulations}

Tofu preparation is closely related to the manufacture of soy milk, because making soy milk is the initial phase from tofu. The principle of tofu coagulation is actually very simple. After soybeans was crushed, the result is extracted so as to obtain the essence of soy milk. Then add the coagulant and precipitated. The precipitate is printed and pressed, after the water is removed, the tofu is obtained. The process of coagulation of tofu can be seen in Figure 2.

\section{Tofu extraction to antioxidant analysis}

The extraction is carried out to isolate antioxidant compounds. The extraction methods used were (1) the extraction method using ultrasonic and (2) maceration extraction method, $100 \mathrm{gr}$ sample were blended until slurry formed, then macerated in $250 \mathrm{~mL}$ of $70 \%$ ethanol for 24 hours, then filtered and the filtrate accommodated. Residue was added with $100 \mathrm{~mL} 70 \%$ of ethanol, then it is macerated for 24 hours. Second residue added $100 \mathrm{~mL} 70 \%$ of ethanol, then filtered again. The filtrate of the maceration was concentrated using a rotary vacuum evaporator to obtain a thickened extract. The following instruments are used in the extraction process step (1) ultrasonic extraction method
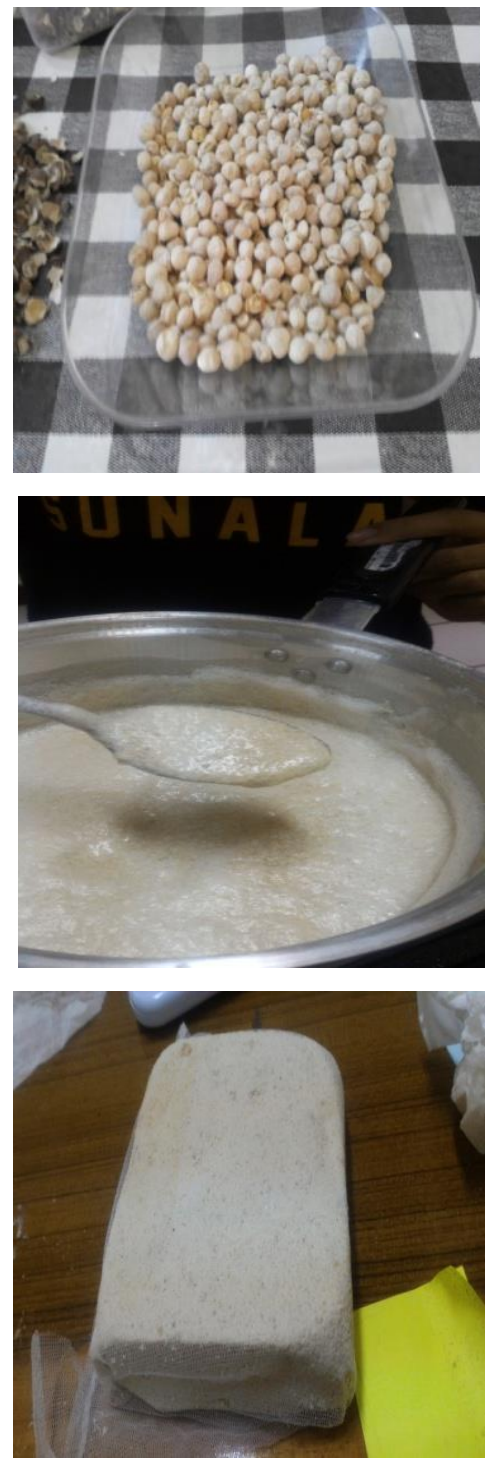
Figure 2. The coagulation process from soy milk to tofu by kelor seeds

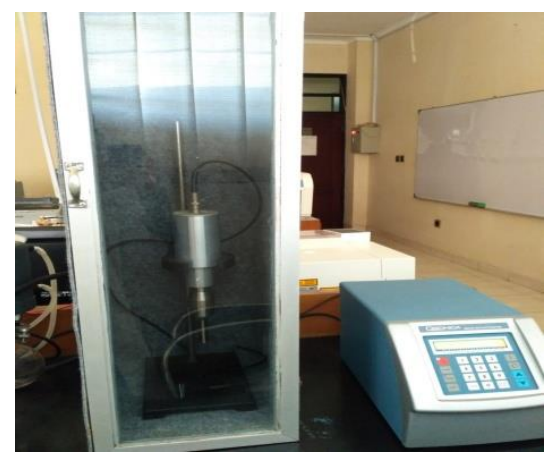

Figure 3. Extraction with ultrasonic method

\section{Antioxidant analysis with DPPH Method} [5]

The antioxidant activity analysis from tofu by knowing the concentration which can inhibit free radical. A concentration has been obtained for the preparation of an initial stock solution. The concentrations of the stock solution represent the inhibitory power. At the initial concentration of $2000 \mathrm{ppm}$, the inhibitory power of tofu is $93.553 \%$ while at 125 ppm concentration, the inhibitory power of tofu is $22.208 \%$.

\section{RESULTS AND DISCUSSION}

In this research, the extraction method using ultrasonic is chosen because it can produce the extract as expected. The form of thick brownish yellow liquid produced by ultrasonic methods. In addition, the ultrasonic method can produce enough yield for further analysis. The extraction process for 30 minutes with a large amplitude of $50 \%$. The ratio between tofu and solvent was 1:3 [4]. The method of multilevel maceration extraction using $n$ - hexane, $70 \%$ of acetone and $96 \%$ of ethanol yielded the tofu extract of $0.23 \mathrm{gr}$ per 100 gram of tofu sample (b/b), the amount of yield is small but has a high degree of purity in the isoflavone content.

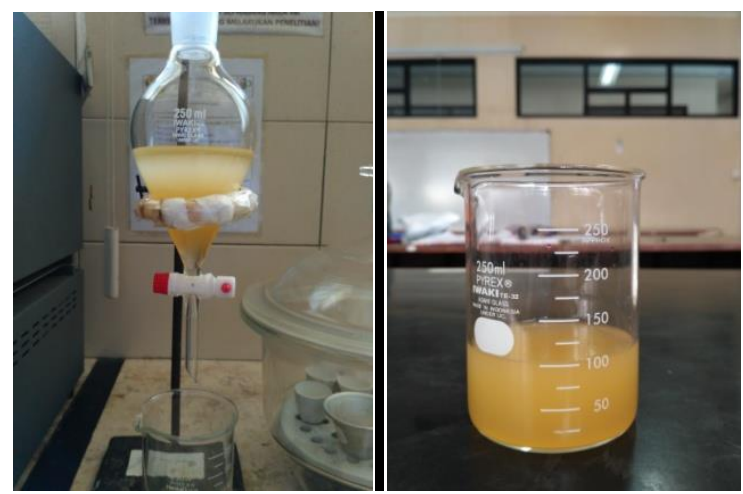

Figure 4. Maceration extraction (i) a color during maceration extraction; (ii) a color of extract when maceration complete

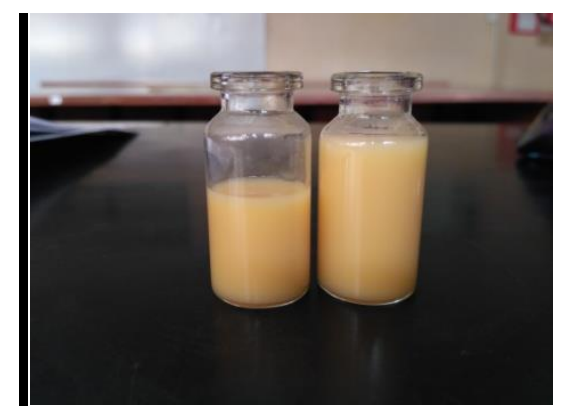

Figure 5. Tofu extracts from kelor coagulant

\section{Determination of extract concentration for IC50 calculation}

Absorbance readings at each concentration were performed using a UVVis spectrophotometer. According to [5], the wavelength used to measure DPPH absorbance is $517 \mathrm{~nm}$. The presence of antioxidant content in Moringa tofu extract will change the color purple in DPPH to yellow. The color changes that occur will be measured by using a 
spectrophotometer so that the percentage of inhibition can be calculated.

Table 2. Antioxidant Analysis

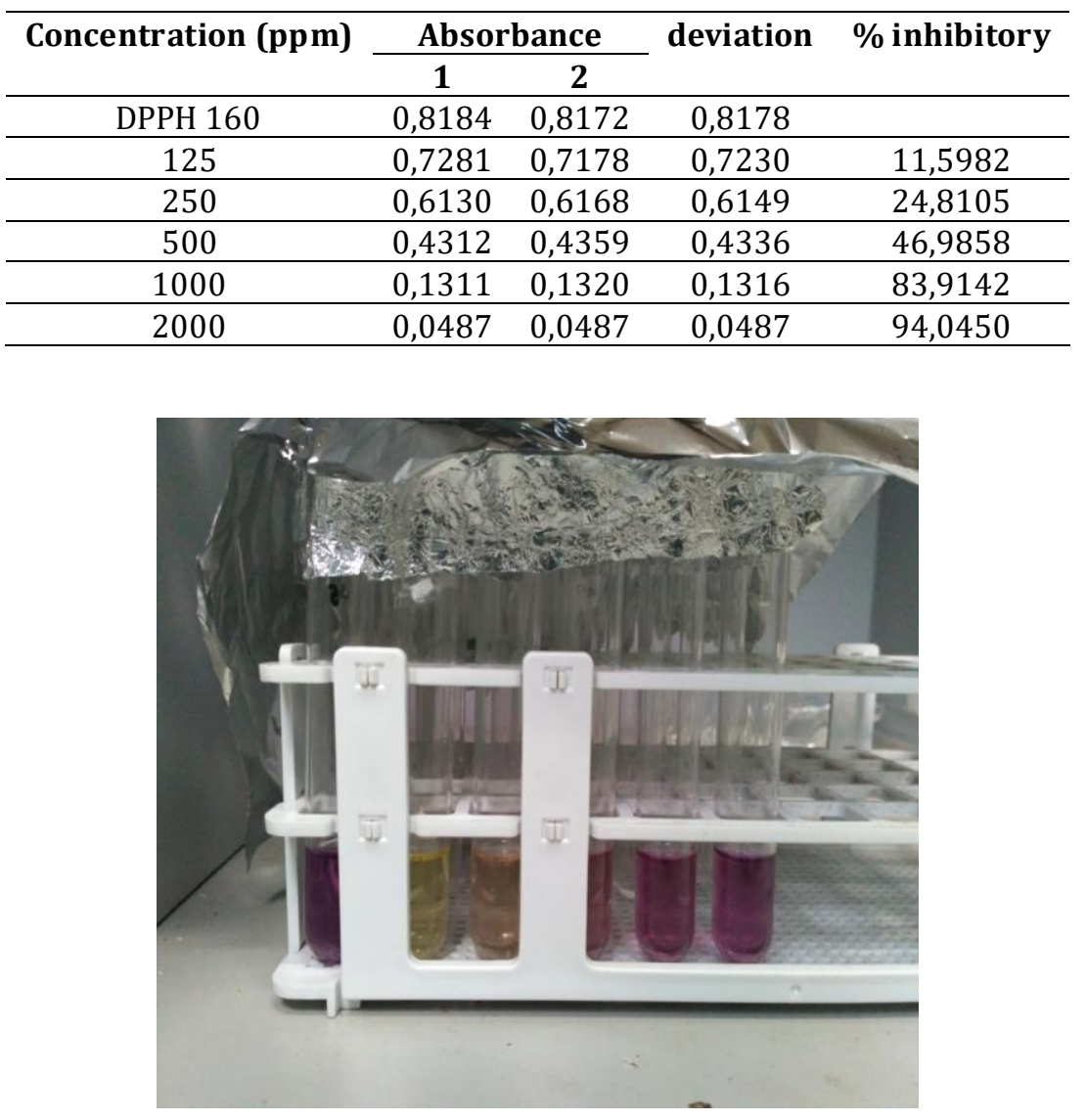

Figure 6. Discoloration of tofu extract in DPPH

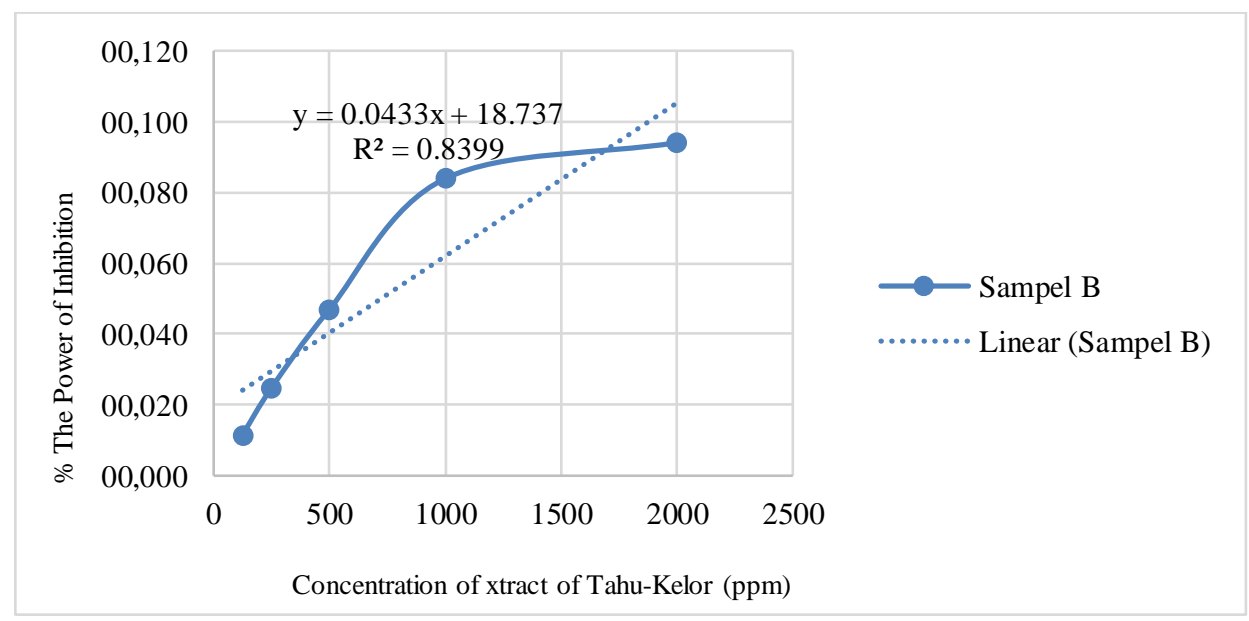

$Y=0,0433 X+18,737$, then, $50=0,0433 X+18,737$, so $X=722,01$ 
Figure 7. Extract concentration for IC50 calculation

\begin{abstract}
Determination of extract concentration for IC50 calculation measured by using a spectrophotometer so that the percentage of inhibition is 722,01 which concentration needed to 50 $\%$ can inhibit free radical in antioxidants analysis. According to [8], Antioxidant activity reported in oil from the dried seeds is higher than BHT and alpha Tocopherol. Aqueous methanol (80\%) and ethanol $(70 \%)$ extracts of freeze dried leaves showed radical scavenging and antioxidant activities.
\end{abstract}

\section{CONCLUSION}

The research of preparation method on antioxidant analysis from tofu coagulation with moringa seed using multilevel maceration and ultrasonic extraction require preparation time which are categorized same that is 4 days, but extraction from multilevel maceration has the advantage with the result criteria desired form of yellowish brownish extract, high yield value and high purity. the percentage of inhibition using multilevel maceration was 722,01 which is concentration needed to $50 \%$ inhibit free radical in antioxidants analysis.

\section{REFERENCES}

[1] Anwar F, Ashraf M and Bhanger MI. Interprovenance variation in the composition of Moringa oleifera oilseeds from Pakistan. J Am Oil Chem Soc.2005

[2] Goja, A.M. 2013. Physico-chemical properties of oil produced from Moringa oleifera, Jathropa curcas, and Chartamus tinctorius L seed. International journal of advanced research.
[3] Kwon,Y.S.,and Kim,C.M., Antioxidant Constituent from the Steam of Sorghumbicolor,Arch.Pharm.res.26 (7): 535-539

[4] Mani, S., S. Jaya, and R. Vadivambal. 2007. Optimization of solvent Extraction of Moringa (Moringa Oleifera) Seed Kernel Oil using response Surface Methodology. Journal of Food \& Bioproducts Processing: Transactions of the Institution of Chemical Engineers Part C, Vol. 85 (328).

[5] Molyneux, P., 2004, The Use of The Stable Free Radical Diphenylpicrylhydrazyl (DPPH) for Estimating Antioxidant Songklanakarin, J. Sci. Technol.

[6] Nasir, Subriyer. 2010. Pemanfaatan Ekstrak Biji Kelor (Moringa oleifera L.) Untuk Pembuatan Bahan Bakar Nabati. Teknik Kimia. Universitas Sriwijaya.

[7] Palafox, O. J., J. M. Diaz, E. A. F. Coronel, J. C. S. Rivero, C. R. Atoche, P. A. and Escoffie, J. A. R. Uribe. 2012. Extraction and Characterization of Oil from Moringa oleifera Using Supercritical and Traditional Solvents. Facultad de Ingenieria Quimica, Universidad Autonoma de Yucatan. Mexico.

[8] Siddhuraja P and Becker K. Antioxidant properties of various solvent extracts of total phenolic constituents from three different agro climatic origins of drumstick tree (Moringa oleifera lam) leaves. J Agric Food chem.2003 